\title{
Contribution of conditioned opioid analgesia to the shock-induced associative US-preexposure deficit
}

\author{
LOUIS D. MATZEL, STEVE C. HALLAM, and RALPH R. MILLER \\ State University of New York at Binghamton, Binghamton, New York
}

\begin{abstract}
The modulatory effect of conditioned opioid analgesia on learning in the US-preexposure paradigm was examined in three experiments using water-deprived rats. In Experiment 1, it was found that tailflick latencies increased immediately after the rats were exposed to a context in which footshock had previously been administered. Prolonged nonreinforced exposure to the context attenuated this analgesia. Experiment 2 tested the possibility that the effectiveness of CS-US pairings in an excitatory context might be reduced by a conditioned analgesic response that lessens the perceived intensity of the US. Administration of the opiate antagonist naloxone prior to CS-US pairings in the excitatory context reduced the US-preexposure deficit-that is, the retarded response to the CS-but did not eliminate it, suggesting that part of the observed deficit resulted from conditioned activation of the endogenous opioid system. In Experiment 3, it was found that exposure to the excitatory context immediately prior to a CS-US pairing in an associatively neutral context resulted in a conditioned response deficit, indicating that the analgesia elicited by the excitatory context was sufficient to reduce US effectiveness. In combination with other recent reports, these results suggest that the associative deficit resulting from preexposure to a shock US may, in certain instances, represent the sum of several different associative processes.
\end{abstract}

According to Rescorla and Wagner's (1972) formulation, unsignaled exposure to an unconditioned stimulus (US) allows the context in which the US is presented to acquire associative strength. That is, the static environmental cues become good predictors of the US. Moreover, Rescorla and Wagner hypothesized that stimuli compete for the limited amount of associative strength that a given US can support. Consequently, any subsequent pairings of a conditioned stimulus (CS) with the preexposed US in the excitatory context will result in attenuated (blocked) acquisition of excitatory associative strength by the nominal CS because much of the available associative strength already will have been allocated to the contextual stimuli. Evidence for this learning-based account of the USpreexposure deficit has been provided in numerous reports demonstrating a loss of retardation either when the context was extinguished prior to the CS-US pairings of the retardation test or when the context used for the CS-US pairings was dissimilar to that of the US-alone exposures (e.g., Hinson, 1982; Randich, 1981; Randich \& LoLordo, 1979; Tomie, 1976).

Several recent reports, however, have questioned the assumption that the US-preexposure deficit represents a

Support for this research was provided by NSF Grant BNS 86-00755. L. D. Matzel was supported by a SUNY Dissertation Year Fellowship. We are appreciative of technical advice from Tim Cannon. Thanks are extended to Todd Schachtman for a critical review of an earlier manuscript and to Harry Fowler for valuable discussion of this work. Requests for reprints should be addressed to Ralph R. Miller, Department of Psychology, SUNY-Binghamton, Binghamton, NY 13901. central associative failure. For instance, Timberlake (1986) proposed that failure to respond to a CS paired with a food US in a context that was already predictive of the US arose from response competition (also see Locurto, Travers, Terrace, \& Gibbon, 1980). As support for this alternative view, Timberlake reported that changes in the stimulus conditions after the CS-US pairings, such that the context was no longer a good predictor of the US, resulted in enhanced responding to the CS. Similarly, Matzel, Brown, and Miller (1987) argued that the USpreexposure deficit represented a response failure as opposed to a learning failure (also see Gibbon \& Balsam, 1981; Jenkins, 1984; Miller \& Schachtman, 1985). In a test of this hypothesis, Matzel et al. observed recovery from US-preexposure-induced retardation when the CS training context was extinguished after the CS-US pairings of the retardation test.

In Matzel et al.'s (1987) study, animals that received contextual extinction after CS training did not differ significantly from animals that had received contextual extinction prior to CS training. However, the response level attained by animals that received postconditioning contextual extinction was numerically lower than that of animals that had received contextual extinction prior to CS training, a result that was consistent throughout numerous unreported pilot studies. Accordingly, Matzel et al. suggested that the shock-induced US-preexposure deficit was determined by multiple factors. Contextual extinction prior to CS training would be expected to reduce both the context's competitive advantage in accruing associa- 
tive strength and its ability to mask a learned response, and this treatment appeared to be more effective in reversing the observed deficit than was contextual extinction after CS training which should influence only performance factors. Matzel et al. therefore concluded that the USpreexposure deficit probably represented a learning as well as a performance failure. The learning component of the deficit apparently stems from an associative failure arising from a competition for associative strength at the level of information processing, as implied by Rescorla and Wagner (1972). Also compatible with the Rescorla and Wagner (but not explicitly stated in their model) is the possibility that a variety of internal and external preparatory responses (Marlin, Berk, \& Miller, 1978; Perkins, 1968) may reduce the effectiveness of the US in a context in which unsignaled USs have been presented. Moreover, these responses would be expected to extinguish along with the contextual stimuli if nonreinforced exposure to the context occurred prior to CS training. However, unlike competition for response strength at the time of CS testing, such an adaptation-based reduction in associative strength would not be reversed by extinction of the CS conditioning context after CS training.

An excitatory context is known to elicit behavior that is distinctly different from that seen in a neutral context (Grau \& Rescorla, 1984; Konorski, 1967). Such behavior at the time of CS training might be expected to modify the perception of the US and/or distract the animal from the CS such that learning about the CS-US relationship would be impaired (Locurto et al., 1980). Moreover, in addition to postural adjustments, the perceived intensity of a shock US may be modified by central mechanisms. For instance, MacLennan, Jackson, and Maier (1980) demonstrated that analgesia could be classically conditioned to situational stimuli associated with footshock (also see Fanselow, 1984). If such an analgesic response were conditioned to the CS-training context in Matzel et al.'s (1987) experiments, it may have reduced the ability of the US to support conditioning, thereby explaining why extinction of the excitatory CS-training context prior to CS-US pairings tended to result in a larger response to the CS than did extinction of the context after CS-US training.

Experiment 1 tested the possibility that conditioned analgesia may be evoked by a context in which unsignaled shock previously has been presented, and whether this analgesia is attenuated by nonreinforced exposure to the context. This is essentially a replication of a study by Fanselow (1984), using the parameters employed by Matzel et al. (1987) to demonstrate an associative USpreexposure deficit. Since other researchers (e.g., Matzel et al., 1987; Randich \& LoLordo, 1979) have demonstrated that contextual extinction prior to CS-US pairings reduces the response deficit associated with US preexposure, this study serves as a critical first step in determining whether analgesia contributes to the USpreexposure deficit observed with electric shock as the US.

\section{EXPERIMENT 1}

In this experiment, using parameters identical to those of Matzel et al. (1987), all animals were given US preexposure in one of two contexts (Context A or Context C). Half of the animals preexposed to shock in Context A subsequently were given nonreinforced exposure to that context in order to extinguish associations between Context A and footshock. All animals were then briefly exposed to Context $A$ and immediately thereafter given a tailflick test for analgesia. Lower pain sensitivity (longer tailflick latencies) in animals with intact Context A-shock associations would suggest the existence of conditioned analgesia at the time when CS-US pairings would normally occur in a typical US-preexposure study. The animals that received shock in Context $C$ would not be expected to show an analgesic response to Context $\mathrm{A}$, and therefore served as a control for handling and the nonassociative effects of shock.

\section{Method}

Subjects. Eighteen male and 18 female, naive, Sprague-Dawleyderived rats bred in our colony served as subjects. Male and female body-weight ranges were $275-380$ and $185-220 \mathrm{~g}$, respectively. Following a gradual deprivation schedule initiated 1 week prior to Day 1 of the study, all animals received access to water $10 \mathrm{~min}$ per day approximately $1 \mathrm{~h}$ following completion of any experimental session. Purina Lab Chow was freely available in the home cage. Animals were housed individually in hanging wire-mesh cages in a colony maintained on a 16-h:8-h light:dark cycle. All manipulations were conducted near the middle of the light portion of this cycle. Subjects were assigned to treatment groups $(n s=12)$ counterbalanced to the extent possible for sex, litter of origin, body weight, and baseline lick rates prior to differential treatment.

Apparatus. Twelve lick chambers housed in controlledenvironment shells were used. Six of these were clear Plexiglas boxes measuring $22.75 \times 8.25 \times 13.00 \mathrm{~cm}(1 \times w \times h)$ with electrifiable stainless steel grid floors (rods $0.48 \mathrm{~cm}$ in diameter spaced $1.91 \mathrm{~cm}$ center-to-center). These rods were electrically shorted except on days when footshock administration was scheduled, at which time they were connected by NE-2 neon bulbs. Footshock was provided by a high-voltage ac source in series with a 1-M $\mathrm{M}$ resistor and the neon bulbs. A water-filled lick tube was located on one short wall of the box, left-right centered and $3.8 \mathrm{~cm}$ above the grid floor. A lickometer circuit monitored drinking on days for which footshock was not scheduled. A 45- $\mathrm{\Omega}$ speaker, $10 \mathrm{~cm}$ in diameter, was located on the inner wall of the environmental shell directly behind the lick tube. The environmental shell was illuminated by a nominal 7-W (at $120 \mathrm{~V} \mathrm{ac}$ ) white light bulb driven at $57 \mathrm{~V}$ ac. Background noise, produced by a ventilation fan, was $70 \mathrm{~dB}(\mathrm{C})$ (re SPL).

The remaining six lick chambers were $30-\mathrm{cm}$-long troughs made of black Plexiglas end walls, a clear Plexiglas ceiling, and stainless steel side walls in a truncated-V shape. Each interior was $28 \mathrm{~cm}$ high, $5.25 \mathrm{~cm}$ wide at the bottom, and $21.50 \mathrm{~cm}$ wide at the top. The floor consisted of two 2-cm-wide parallel metal plates separated by a $1.25-\mathrm{cm}$ gap. The metal walls and floor were electrifiable by way of a high-voltage ac source in series with a 1-MQ resistor and an NE-2 neon bulb. A water-filled lick tube connected to a lickometer circuit protruded through one end wall, left-right centered and $3.50 \mathrm{~cm}$ above the floor. The environmental shells housing these enclosures each contained a speaker configuration identical to that found in the clear chambers; background noise was $70 \mathrm{~dB}(\mathrm{C})$. The shell was lit by a nominal 7-W (at $120 \mathrm{~V}$ ac) white light bulb driven 
at $57 \mathrm{~V}$ ac. The bulb was attached to the environmental shell such that only light reflected off the dull white ceiling of the shell entered the chamber, resulting in a dim interior relative to that of the clear chambers.

Twelve additional chambers, highly dissimilar from the 12 lick chambers, were used for administration of the USs outside the conditioning context. They consisted of a $50 \times 8.2 \times 50 \mathrm{~cm}(\mathrm{l} \times \mathrm{w} \times \mathrm{h})$ stalls with flat gray Plexiglas walls and floors composed of 0.64 cm-diam electrifiable grids (spaced $1.59 \mathrm{~cm}$ center-to-center) interconnected by NE-2H neon bulbs. Unlike the clear lick chambers, these grids ran the length of the stall. There were no lick tubes in these enclosures. These apparatus were housed in a large room that was brightly illuminated by overhead fluorescent lights. The ambient sound level was $56 \mathrm{~dB}(\mathrm{C})$.

The tailflick device consisted of a metal box that supported a $46 \times 16 \mathrm{~cm}(1 \times w)$ aluminum plate. Twenty centimeters from the end of the plate, a variable intensity $150-\mathrm{W}$ (nominal) projector lamp was mounted under the plate with light from the bulb passing through a 3-mm aperture. A rat could be placed in one of six commercially manufactured Plexiglas restraining tubes (Fisher, 01-280-10) which rested on the surface of the aluminum plate such that the rat's tail extended over the aperture. When activated, the intensity of the lamp was permanently set such that the average latency of naive rats to tailflick was approximately $7 \mathrm{sec}$.

Procedure. On Days 1-4, every subject was placed for $20 \mathrm{~min}$ in each of the three contexts. The target context to be used for US preexposure was designated Context $\mathrm{A}$ (counterbalanced within groups for clear and V-shaped lick chambers); the remaining lick enclosure was designated Context $B$. The nontarget conditioning stalls were designated Context C. Order of exposure was A-C-B on Days 1 and 3 and B-C-A on Days 2 and 4. Lick tubes were present in Contexts A and B. Approximately 60 min following each of these sessions, all animals were placed in one of the Plexiglas restraining tubes for $10 \mathrm{~min}$ in order to habituate them to the tube. The tube rested in place on the tailflick apparatus. The projector bulb was not activated during these sessions. After Day 4, Context B was not used in this experiment; the animals were adapted to this context only to maintain comparability to prior (Matzel et al., 1987) and subsequent (Experiments 2 and 3) studies.

Following this initial adaptation, all animals received 6 days (Days 5-10) of US preexposure. Groups + A/A and + Ae/A received this preexposure in Context $A$ (therefore designated by $+A$ ); the remaining animals, Group $+C / A$, received identical treatment in Context C. During each of these 60 -min sessions, all animals received six unsignaled, 0.8-mA cc, 60-Hz, 500-msec footshocks. The footshocks were pseudorandomly scheduled throughout each session with a mean interstimulus interval of $8 \mathrm{~min}$ and a range of 4-12 min. On Days 3 and 5 of this treatment, the first shock was scheduled within 5 sec of the start of the session.

On Days 11-18, Group + Ae/A was given nonreinforced exposure to Context $A$. This contextual extinction treatment consisted of placing animals in Context $A$ for 90 min on each of 8 consecutive days in the absence of any CS or US presentations. During this treatment, the remaining groups remained in their homecages.

On Day 19, all animals were placed in Context A for $90 \mathrm{sec}$. Immediately following removal from Context $A$, the rats were placed in their restraining tubes on the tailflick device. The projector lamp was activated, and the latency to withdrawal of the tail from the beam of light was recorded. Five such latencies were recorded for each rat. The first measure was taken midway between the base and the tip of the tail. Subsequent measures were taken at 1-cm increments toward the tip with $30-\mathrm{sec}$ intertest intervals. A trial was terminated if a tailflick did not occur within $15 \mathrm{sec}$. In practice, this latency was reached on less than $10 \%$ of the trials and almost exclusively by subjects in Group $+\mathbf{A} / \mathbf{A}$.

\section{Results and Discussion}

A mean latency was determined for each subject by averaging its five tailflick latencies. Two subjects were discarded due to illness during the US-preexposure phase. Figure 1 depicts the mean tailflick latency for each group. $A$ one-factor analysis of variance (ANOVA) indicated a significant effect of treatment $[F(2,31)=8.38$, $p<.001]$. Planned comparisons found that the latencies of Groups + Ae/A and + A/A differed $[F(1,31)=12.85$, $p<.01]$, as did those of Groups $+\mathrm{C} / \mathrm{A}$ and $+\mathrm{A} / \mathrm{A}$ $[F(1,31)=12.70, p<.01]$. Groups $+\mathrm{Ae} / \mathrm{A}$ and $+\mathrm{C} / \mathrm{A}$ did not differ $[F(1,31)=0.03]$.

Consistent with MacLennan et al. (1980) and Fanselow (1984), the present study obtained increased tailflick latencies indicative of an analgesic response elicited by the context in which unsignaled shocks previously had been administered (Group +A/A). Additionally, nonreinforced exposure to that context prior to testing was found to eliminate this analgesic response to the context (Group $+\mathrm{Ae} / \mathrm{A})$. These results raise the possibility that a conditioned response (CR) based on CS-US pairings administered in Context $A$ after unsignaled shock presentations in that context may be attenuated in part due to an affectively less intense US at the time of CS training. As hypothesized by MacLennan et al., conditioned analgesia may well have the potential to contribute to the US-preexposure deficit. However, in view of Matzel et al.'s (1987) finding of a partial recovery from this deficit following contextual extinction after CS-US pairings, reduced affective value of the US cannot account for the entire associative US-preexposure deficit.

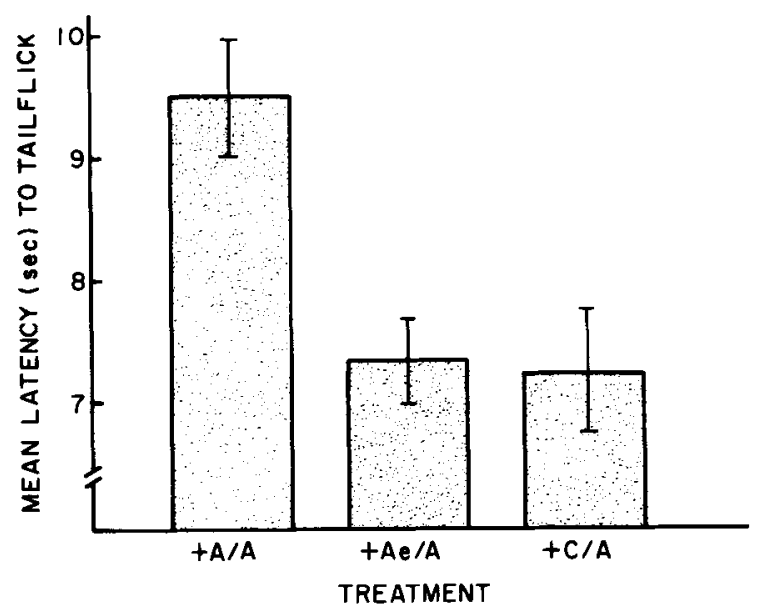

Figure 1. Mean latencies to tailnick after exposure to Context $A$ in Experiment 1. Groups + A/A and + Ae/A were preexposed to unsignaled footshock in Context A, and Group + C/A was preexposed to footshock in Context C. A tainick test was given immediately after a 90-sec exposure to Context $A$ with no shock presentations. Prior to exposure to Context $A$ on the taininick test day, Group + Ae/A received nonreinforced exposure, that is, extinction, to Context $A$. Brackets denote standard errors. 


\section{EXPERIMENT 2}

Although Experiment 1 demonstrated that an analgesic response can be conditioned to situational stimuli with shock parameters that result in a US-preexposure deficit (Matzel et al., 1987), and that this response can be extinguished with nonreinforced exposure to the context, it cannot be concluded that this analgesic response is sufficient to reduce the ability of footshock to support learning about the CS-US relationship. Matzel and Miller (1987) found that the conditioned analgesia elicited by contextual stimuli associated with this intensity and distribution of footshocks is opioid in nature. Specifically, they reported that the opiate antagonist naloxone attenuated the analgesic response to the context in which the shocks had previously been administered. If this analgesia is sufficient to reduce learning by lessening the perceived severity of the shock US, then administration of naloxone prior to CS-US pairings in the aversive context should attenuate any portion of the US-preexposure deficit attributable to conditioned analgesia.

In Experiment 2, two groups of animals were preexposed to shock in Context $A$ (Groups $+\mathrm{A} / \mathrm{nA}$ and $+\mathrm{A} / \mathrm{sA}$ ) and two groups were preexposed to shock in Context $\mathrm{C}$ (Groups $+\mathrm{C} / \mathrm{nA}$ and $+\mathrm{C} / \mathrm{sA}$ ) using parameters identical to those of Experiment 1. Subsequently, all animals received a single CS-US pairing in Context A. Prior to placement in Context A on the CS training day, Groups $+\mathrm{A} / \mathrm{nA}$ and $+\mathrm{C} / \mathrm{nA}$ received an injection of the opiate antagonist naloxone, and Groups $+\mathrm{A} / \mathrm{sA}$ and $+\mathrm{C} / \mathrm{sA}$ received an injection of saline. All animals were later tested in a neutral context for suppression of ongoing drinking in the presence of the CS. An enhanced response to the $\mathrm{CS}$ in Group $+\mathrm{A} / \mathrm{nA}$ relative to that of Group $+\mathrm{A} / \mathrm{sA}$ would be indicative of a conditioned analgesic component of the US-preexposure deficit. The extent to which associative US-preexposure effects contributed to the potential deficit would be indexed relative to animals that received US preexposure in Context $C$, since, because Context $A$ would be associatively neutral, no such deficit would be expected in these animals.

\section{Method}

Subjects and Apparatus. Thirty-six male and 36 female rats of the same general description as those used in Experiment 1 served as subjects. The apparatus was identical to that used in Experiment 1, except that the restraining tubes and tailflick device were not used in this study.

Procedure. Initial acclimation to Contexts $A, B$, and $C$ was conducted on Days 1-4, as in the previous study. Latency to complete an initial and second 25 licks in Context B was recorded each time the animal was placed in that context throughout the study. Subsequently, two groups of subjects (Groups $+\mathrm{A} / \mathrm{nA}$ and $+\mathrm{A} / \mathrm{sA}$ ) received 6 days of unsignaled shock exposure in Context $A$ and two groups (Groups $+\mathrm{C} / \mathrm{nA}$ and $+\mathrm{C} / \mathrm{sA}$ ) received identical treatment in Context C. Shock intensity and scheduling was the same as that of Experiment 1. On Day 11 (the day following the last unsignaled shock session), Groups $+\mathrm{A} / \mathrm{nA}$ and $+\mathrm{C} / \mathrm{nA}$ received a 1 - $\mathrm{mg} / \mathbf{k g}$-body-weight intraperitoneal injection of naloxone hydrochloride dissolved in $1 \mathrm{mg} / \mathrm{cc}$ of isotonic saline. Groups $+\mathrm{A} / \mathrm{sA}$ and $+\mathrm{C} / \mathrm{sA}$ received a $1-\mathrm{cc} / \mathrm{kg}$-body-weight injection of isotonic saline and were then returned to their home cages. Fifteen minutes following the injection, each animal was placed in Context $A$ for $10 \mathrm{~min}$. Sixty seconds after placement in Context $\mathrm{A}$, all animals received a single CS-US pairing. The CS was a $5-\mathrm{sec}, 1500-\mathrm{Hz}$ tone $12 \mathrm{~dB}(\mathrm{C})$ above the background noise level. The US was the same $0.8-\mathrm{mA}, 500$-msec shock that had been used during the preconditioning phase. The onset of the US was concurrent with the offset of the tone.

On Day 12, all animals were placed in Context B for $20 \mathrm{~min}$ to ensure stable baseline lick rates in that context. The animals were tested for lick suppression in the presence of the tone on Day 13 by being placed in Context $B$ and allowed to emit 25 licks. Upon completion of the 25th lick, the tone was presented; it remained on until another 25 licks were completed. A maximum latency of $1,200 \mathrm{sec}$ was allowed, although in practice no animals in this or subsequent studies achieved this latency. The animals were tested in Context B in order to avoid summation of CS and context associative strengths that might have obscured evidence of the USpreexposure effect.

To improve normality of within-group distributions, thereby permitting the use of parametric statistics, all lick latencies were converted to $\log$ scores.

\section{Results and Discussion}

No between-group differences were apparent in latencies to emit the initial or second 25 licks in Context B on the day prior to testing or in latencies to complete the initial 25 licks prior to CS presentation on the test day $(F \mathrm{~s}<1)$. Figure 2 presents the mean latency to complete 25 licks in the presence of the tone CS for each group. A two-factor ANOVA indicated a significant effect of context of preexposure prior to CS training in Context $A$ $[F(1,68)=39.22, p<.001]$. The effect of type of injection prior to the CS-US pairing was also reliable

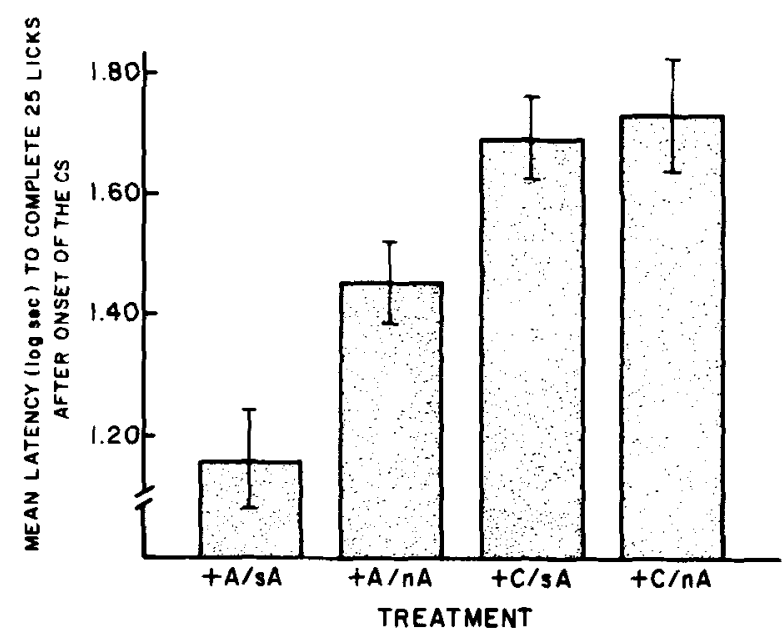

Figure 2. Mean latencies to complete 25 licks in the presence of the tone CS in Experiment 2. Groups +C/sA and +C/nA received US preexposure in Context $C$, and Groups $+\mathbf{A} / \mathbf{s A}$ and $+\mathbf{A} / \mathbf{n A}$ recived US preexposure in Context $A$, the $C S$ conditioning context. All animals subsequently received a CS-US poiring in Context $A$. Immediately prior to this pairing, Groups $+\mathrm{A} / \mathrm{nA}$ and $+\mathrm{C} / \mathrm{nA}$ received an injection of the opiate antagenist naloxone and Groups $+\mathrm{A} / \mathrm{sA}$ and $+\mathrm{C} / \mathrm{sA}$ received an injection of saline. Brackets represent standard errors. 
$[F(1,68)=6.08, p<.05]$, as was the interaction of context with type of injection $[F(1,68)=4.17, p<.05]$. Planned comparisons were used to assess between-group differences. Group $+\mathbf{A} / \mathbf{n A}$ displayed higher suppression to the tone CS than did Group $+\mathrm{A} / \mathrm{sA}[F(1,68)=9.82$, $p<.01]$. Groups $+\mathrm{C} / \mathrm{nA}$ and $+\mathrm{C} / \mathrm{sA}$ did not differ $[F(1,68)=1.05, p>.25]$. This lack of difference was probably not due to any behavioral ceiling, because the single CS-US pairing used in this study produced suppression that was appreciably less than that obtained in pilot work, which, except for a longer CS duration, had identical parameters. Group $+\mathrm{A} / \mathrm{nA}$ differed from both Group $+\mathrm{C} / \mathrm{nA}[F(1,68)=9.16, p<.01]$ and Group + C/sA $[F(1,68)=7.31, p<.05]$. Similarly, Group $+\mathrm{A} / \mathrm{sA}$ differed from Groups $+\mathrm{C} / \mathrm{nA}$ and $+\mathrm{C} / \mathrm{sA}$ $[F \mathrm{~s}(1,68)=37.98$, and 34.08 , respectively; $p s<.001]$.

The results of Experiment 2 suggest that an injection of the opiate antagonist naloxone prior to CS training in an excitatory context does enhance learning by attenuating the analgesic response that otherwise would reduce the perceived intensity of the US. However, naloxone may have an additional effect. Under some circumstances, large doses of naloxone appear to enhance a shock-US's ability to enter into an association (Lester \& Fanselow, 1986; Vigorito \& Ayres, 1987), possibly as a result of increased pain sensitivity (but see Jacob, Tremblay, \& Colombel, 1974). Such an increase in the affective value of the footshock could have contributed to the augmented learning seen in animals treated with naloxone prior to CS training, by supporting a higher level of learning and/or through an "unblocking" mechanism (e.g., Dickinson, Hall, \& Mackintosh, 1976), either of which might occur independently of any attenuation of the conditioned analgesia elicited by the context. The relative contribution of each of these factors cannot be determined on the basis of the results of Experiment 2. However, the dose of naloxone used here was intentionally low in order to reduce the relative contribution of these later mechanisms. Although it did not appear that naloxone in itself was sufficient to induce an enhanced degree of conditioning (as indicated by a comparison of Groups $+\mathrm{C} / \mathrm{sA}$ and $+\mathrm{C} / \mathrm{nA}$ ), the possibility that unblocking might account for the enhanced response observed in Group $+A / n A$ could not be totally discounted.

\section{EXPERIMENT 3}

Experiment 3 was an attempt to determine whether conditioned analgesia contributes to the retarded acquisition of associative strength by a CS trained in a context in which shock has been administered without the added complication of possible hyperalgesia elicited by naloxone. In Experiment 2, the degree of retardation observed in Group $+\mathrm{A} / \mathrm{sA}$ relative to Group $+\mathrm{C} / \mathrm{sA}$ could not be regarded as indicative of conditioned analgesia exclusively, because blocking of the CS by the conditioning context (e.g., Randich \& LoLordo, 1979) and/or comparator processes (Matzel et al., 1987) could have in- fluenced these two groups differentially. To minimize the contribution of factors other than the conditioned analgesic response, all animals in Experiment 3 received a CS-US pairing in a neutral context immediately after a brief exposure to a different context that was either excitatory or neutral. Matzel and Miller (1987) have reported that the conditioned analgesia elicited by the excitatory context in this situation is maximal somewhere between 10 and $90 \mathrm{sec}$ after exposure to the context (also see Maier, Drugan, \& Grau, 1982; Ross \& Randich, 1984). In Experiment 3, all animals were preexposed to shock either in Context $A$ (Group + A/A) or in Context $C$ (Group $+\mathrm{C} / \mathrm{A}$ ). On the day following the last preexposure session, all animals were placed in Context A for $90 \mathrm{sec}$ and then were immediately moved to Context $B$, which was associatively neutral for all animals. A single CS-US pairing was administered $60 \mathrm{sec}$ after placement in this context. If the analgesic response conditioned to an excitatory context was sufficient to reduce the effectiveness of the shock US, a later test of the CS should find an attenuated $C R$ in those animals for which Context $A$ was excitatory (Group $+\mathrm{A} / \mathrm{A}$ ) relative to that found in animals for which Context A was neutral (Group +C/A) even though the actual CS-US pairing occurred in Context $B$.

\section{Method}

Subjects and Apparatus. Eighteen male and 18 female rats served as subjects, and the apparatus was the same as that used in the preceding experiments.

Procedure. The initial 4 days of context and lick adaptation were identical to those of Experiments 1 and 2 . As in those experiments, half of the animals (Group $+\mathrm{A} / \mathrm{A}$ ) received 6 days of US preexposure in Context $A$ and half of them received this exposure in Context $\mathrm{C}$ (Group $+\mathrm{C} / \mathrm{A}$ ). On Day 11, the day following the last preexposure session, all animals were placed in Context $A$ for $90 \mathrm{sec}$, after which they were moved to Context $B$. All animals remained in Context B for 10 min. One minute after placement in Context B, all animals received a single CS-US pairing consisting of the 5-sec tone employed in Experiment 2 and the 0.8-mA shock used for the preexposure sessions.

On the day following this CS-US pairing, all animals received a 20-min session in Context B to ensure stable lick rates there. On the subsequent day, all animals were tested for suppression to the tone CS in Context B using the procedure employed in Experiment 2 .

\section{Results and Discussion}

No between-group differences were apparent in latencies to emit the initial or second 25 licks in Context B on the day prior to testing or in the initial 25 licks prior to $C S$ presentation on test day $(F \mathrm{~s}<1)$. However, Group +A/A exhibited less suppression in the presence of the CS with a mean latency $( \pm S E)$ of $1.86( \pm .14)$ $\log$ sec to complete 25 licks than did Group $+\mathrm{C} / \mathrm{A}$ with a mean latency of $2.21( \pm .11) \log \sec [F(1,34)=4.28$, $p<.05$ ].

Exposure to a context that is known to elicit an analgesic response (Experiment 1) was apparently sufficient to decrease the effectiveness of the shock US so that learning was attenuated when a CS-US pairing was ad- 
ministered soon afterwards in a neutral context. Numerous studies have found that a context change between initial US preexposure and CS-US pairings attenuates the preexposure deficit (e.g., Hinson, 1982; Matzel et al., 1987). Although we also observed such a context-specific effect in our Experiment 2, Experiment 3 suggests that a transfer of analgesia-induced attenuation of learning is possible because of the persistence of the analgesic response, provided that the animal is exposed to the excitatory context immediately prior to CS training in the neutral context. Consistent with the present implication that an activated endogenous analgesic system can interfere with learning about a shock US, Drugan and Maier (1983) found that an opioid-based analgesic reaction interfered with a shock-motivated avoidance response. Paralleling these observations, Siegal (1977) concluded that drug tolerance could be conditioned to a context in which the drug was previously administered, and that exposure to that context could temporarily reduce the effectiveness of drug administration.

There is an alternative to conditioned analgesia as an explanation of the findings of Experiment 3 . The decrement in suppression could, in principle, be explained by serial blocking by the excitatory context. In a similar vein, Wagner (1981), has suggested that memorial "priming," that is, expectancy, of a US reduces its effectiveness and thereby its ability to support conditioning. However, the time needed to shift contexts (approximately $5 \mathrm{sec}$ ), plus the 60-sec delay of CS onset following placement of the subjects in Context B on the CS training day, resulted in a 65 -sec delay between exposure to the excitatory context and the onset of the CS, thereby rendering serial blocking or US-trace priming unlikely explanations of these results.

\section{GENERAL DISCUSSION}

The current results suggest that the response deficit that occurs when CS-shock pairings take place in a context in which unsignaled shocks have previously been presented is, in part, due to modulation of learning by conditioned analgesia. In previous research, Matzel et al. (1987) employed the same US-preexposure parameters used in the present experiments, and found that much of the US-preexposure deficit resulted from a failure of a learned association to be manifest in behavior. However, it was speculated that the observed deficit was determined by multiple factors, because recovery of the conditioned response was less for animals that received contextual extinction after CS-US pairings than for animals that had received contextual extinction before CS training. Matzel et al. further speculated, on the basis of the data and suggestion of MacLennan et al. (1980), that analgesia conditioned to the contextual stimuli may have reduced the perceived intensity of the shock US, which in turn would have attenuated acquisition of the CS-US association.

The present Experiment 1 showed that the shock preexposure employed in the Matzel et al. (1987) study was sufficient to elicit an analgesic response, and that this response was extinguished by nonreinforced exposure to the context. These findings are consistent with those of previous work (e.g., Maclennan et al., 1980; Fanselow, 1984). The intent of the subsequent experiments was to determine if this analgesic response was sufficient to attenuate learning a CS-shock association. Previous work (Matzel \& Miller, 1987) had found that the analgesia induced with these parameters was attenuated by the opiate antagonist naloxone. In Experiment 2, we attempted to reduce the apparent acquisition deficit by administering naloxone prior to CS-US pairings in the excitatory context. Although the administration of naloxone had no apparent effect on animals for which the CS training context was associatively neutral, the retarded response in animals for which the context was excitatory was partially attenuated, that is, conditioned responding was enhanced relative to that exhibited by animals that had received saline prior to training in the excitatory context.

In Experiment 3, we tested the possibility that analgesia contributed to the US-preexposure deficit, but we did so without administering naloxone, which had made it difficult to interpret Experiment 2, given that in some cases, naloxone may enhance pain perception. We found that exposure to the context in which unsignaled shocks previously had been administered resulted in a learning deficit when a CS-US pairing was administered immediately thereafter in an associatively neutral context. Specifically, two groups of animals received the same treatment on the CS training day and differed only in whether or not the initial context to which they were exposed had an excitatory history. The response deficit seen in animals exposed to the excitatory context just prior to training in a neutral context would suggest that, due to the persistence of the analgesic response, the analgesia elicited by the excitatory context was sufficient to reduce the effectiveness of the training US, even though these animals were no longer in the presence of the analgesia-eliciting stimuli. The results of Experiment 3, in combination with those of Experiments 1 and 2, provide converging evidence that conditioned analgesia does contribute to the CR deficit that results from preexposure to unsignaled shock. Although Experiments 2 and 3 are subject to interpretations other than those suggested here (see discussion of individual experiments), modulation of US intensity by conditioned analgesia successfully addresses all of these results.

The present experiments were intended to determine whether a conditioned analgesic response elicited by a context in which unsignaled shock previously had been administered contributed to the US-preexposure deficit. The results provide support for the view that activation of the endogenous analgesic system causes a learning deficit, that is, blocking of the CS-US association at the time of CS training, and is consistent with the modification of the Rescorla-Wagner (1972) model proposed by Schull (1979), in which associative competition is mediated by opponent processes. This should not be taken to suggest 
that all instances of blocking by context are mediated by conditioned analgesia; rather, the current results suggest that under certain instances an analgesic response can modulate learning about an aversive US. Moreover, the underlying assumption of these experiments was that compensatory analgesic responses to a context associated with shock might reduce the ability of a shock US to support conditioning. However, it might also be possible that opioids modulate the actual formation of associations, and might therefore influence learning independently of any modulation of perceived intensity of the US.

\section{REFERENCES}

Dickinson, A., Hall, G., Mackintosh, N. J. (1976). Surprise and the attenuation of blocking. Journal of Experimental Psychology: Animal Behavior Processes, 2, 313-322.

Drugan, R. C., MaIER, S. F. (1983). Analgesic and opioid involvement in the shock-elicited activity deficits produced by electric shock. Learming \& Motivation, 14, 30-47.

FANSELOW, M. S. (1984). Shock-induced analgesia on the formalin test: Effects of shock severity, naloxone, hypophysectomy, and associative variables. Behavioral Neuroscience, 98, 79-95.

Gibbon, J., Balsam, P. (1981). Spreading association in time. In C. M. Locurto, H. S. Terrace, \& J. Gibbon (Eds.), Autoshaping and conditioning theory (pp. 219-253). New York: Academic Press.

GraU, J. W., \& Rescorta, R. A. (1984). Role of context in autoshaping. Journal of Experimental Psychology: Animal Behavior Processes, 10 , 324-332.

Hinson, R. E. (1982). Effects of UCS preexposure on excitatory and inhibitory rabbit eyelid conditioning: An associative effect of conditioned contextual stimuli. Joumal of Experimental Psychology: Animal Behavior Processes, 8, 49-61.

Jacob, J. J., Tremblay, E. C., \& Columbel, M. (1974). Facilitation de réactions nociceptives par la naloxone chez la souris et chez le rat. Psychopharmacologia, 37, 217-223.

Jenkins, H. M. (1984). Time and contingency in classical conditioning. Annals of the New York Academy of Sciences, 423, 242-253.

KonORSKI, J. (1967). Integrative activity of the brain. Chicago: University of Chicago Press.

Lester, L. S., FANSELow, M. S. (1986). Naloxone's enhancement of freezing: Modulation of perceived intensity or memory processes. Physiological Psychology, 14, 5-10.

Locurto, C. M., Travers, T., Terrace, H. S., \& GibBon, J. (1980). Physical constraint produces rapid acquisition of pigeon's keypeck. Journal of the Experimental Analysis of Behavior, 34, 13-21.

Maclennan, A. J., Jackson, R. L., \& Maier, S. F. (1980). Conditioned analgesia in the rats. Bulletin of the Psychonomic Society, 15 , 387-390.

Maier, S. F., Drugan, R. C., Grau, J. W. (1982). Controllability, coping behavior, and stress-induced analgesia in the rat. Pain, 12, 47-56.
Marlun, N. A., Berk, A. M., Miller, R. R. (1978). Modification and avoidance of unmodifiable and unavoidable footshock. Bulletin of the Psychonomic Socieny, 11, 203-205.

Matzel, L. D., Brown, A. M., a Miller, R. R. (1987). Associative effects of US-reexposure: Modulation of a conditioned response by an excitatory training context. Joumal of Experimental Psychology: Animal Behavior Processes, 13, 65-72.

MATzel, L. D., MiLler, R. R. (1987). Recruitment time of conditioned opioid analgesia. Physiology \& Behavior, 39, 135-140.

Miller, R. R., Schachtman, T. R. (1985). Conditioning context as an associative baseline: Implications for response generation and the nature of conditioned inhibition. In R. R. Miller \& N. E. Spear (Eds.), Information processing in animals: Conditioned inhibition (pp. 51-88). Hillsdale, NJ: Erlbaum.

Perkins, C. C. (1968). The stimulus conditions which follow learned responses. Psychological Review, 75, 155-172.

RANDiCH, A. (1981). The US preexposure phenomena in the conditioned suppression paradigm: A role for conditioned situational stimuli. Leaming \& Motivation, 12, 321-341.

Randich, A., LoLordo, V. M. (1979). Preconditioning exposure to the unconditioned stimulus affects the acquisition of a conditioned emotional response. Leaming \& Motivation, 10, 245-277.

Rescorla, R. A., WAgner, A. R. (1972). A theory of Pavlovian conditioning: Variations in the effectiveness of reinforcement and nonreinforcement. In A. H. Black \& W. F. Prokasy (Eds.), Classical conditioning II (pp. 64-99). New York: Appleton-Century-Crofts.

Ross, R. T., RANDICH, A. (1984). Unconditioned stress-induced analgesia following exposure to brief footshock. Joumal of Experimental Psychology: Animal Behavior Processes, 10, 127-137.

SCHULL, J. (1979). A conditioned opponent theory of Pavlovian conditioning and habituation. In G. H. Bower (Ed.), The psychology of learning and motivation (Vol. 13, pp. 57-90). New York: Academic Press.

SIEGAL, S. (1977). Morphine tolerance acquisition as an associative process. Joumal of Experimental Psychology: Animal Behavior Processes, 3, 1-13.

Timberlake, W. (1986). Unpredicted food produces a mode of behavior that affects rats' subsequent reactions to a conditioned stimulus: A behavior-system approach to "context blocking." Animal Learning \& Behavior, 14, 276-286.

Tomie, A. (1976). Interference with autoshaping by prior context conditioning. Journal of Experimental Psychology: Animal Behavior Processes, 2, 323-334.

Vigorito, M., \& AYres, J. J. B. (1987). Effect of naloxone on conditioned suppression in the rat. Behavioral Neuroscience, 101, 576-586.

W AGNER, A. R. (1981). SOP: A model of automatic memory processing in animal behavior. In N. E. Spear \& R. R. Miller (Eds.), Information processing in animals: Memory mechanisms (pp. 5-47). Hillsdale, NJ: Erlbaum.

(Manuscript received March 9, 1987; revision accepted for publication May 6, 1988.) 